\title{
Can Environmental Factors Predispose Noncommunicable Diseases?
}

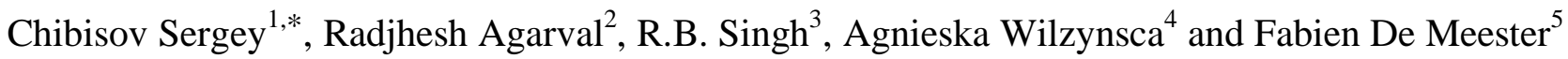 \\ ${ }^{I}$ Russian People's Friendship University of Russia, Moscow \\ ${ }^{2}$ Network of World Doctors, Moscow \\ ${ }^{3,4,5}$ Tsim Tsoum Institute, Krakow, Poland
}

\begin{abstract}
There is marked increase in our knowledge about the role of the environmental factors in the global dimensions of the noncommunicable diseases (NCD) including cardiovascular diseases (CVDs). Recent studies indicate that there is coexistence of nutritional deficiencies and appreciable over-nutrition in association with sedentary behavior due to urbanization and industrialization. Environmental factors including helio-magnetic fluctuations may result into inflammatory dysfunctions in various biological systems. These dysfunctions can manifest in the form of central obesity and overweight in developing countries as well as in high income countries. The Global Burden of Disease Study clearly showed that the gratifying gains in cardiovascular health occurred in developed countries, in association with an epidemic of CVD in the developing world. Singh et al., proposed, modifying the previous hypothesis, that overweight comes first in conjunction with inflammation, hyperinsulinemia, increased angiotensin activity, vascular variability disorders and central obesity followed by glucose intolerance, type 2 diabetes, hypertension, low HDL and hypertriglyceridemia (Metabolic syndrome).This sequence is followed by coronary artery disease(CAD), gall stones and cancers and finally dental caries, gastrointestinal diseases, bone and joint diseases, degenerative diseases of the brain and psychological disorders, during transition from poverty to affluence. It seems that all the NCDs are mediated by inflammation due to interaction of biological systems with environmental factors, including heliomagnetic fluctions. As people become rich, they begin to increase their intake of proinflammatory refined foods; dietary w-6 and trans fat, salt and sugar in the form of ready prepared foods, syrups, dairy products and flesh foods in place of grain and vegetable based diet. There is a greater use of automobiles, television vewing and decrease in sports, walking and dancing as recreation which also enhances the inflammation, dyslipidemia and obesity. These changes in the diet and lifestyle in conjunction with mental strain, and increase in tobacco and alcohol intake as well as heliomagnetic fluctuations, appear to be primary risk factors in the pathogenesis of inflammation and dyslipidemia leading to NCDs.
\end{abstract}

Keywords: Diet, lifestyle, heliomagnetic fluctuations, inflammation, chronic diseases, noncommunicalbe diseases.

\section{INTRODUCTION}

Chronic diseases of affluence or noncommunicable diseases (NCD) are a major impediment to human development, imposing large health and economic burden worldwide [1-7]. These burdens are reciprocal because poverty is a potential cause of NCDs in developed countries and NCDs contribute to poverty. The world has been in a position to learn the role of environmental factors during transition from poverty to economic development and emergence of NCDs [1-8]. The last decade of the last century offered us an opportunity to initiate action to counter growing epidemics of CVD including metabolic syndrome on both sides of the Atlantic [9-12]. When people learned the methods of prevention, there was a decrease in CVD in the western world but obesity continued to increase, resulting into an increase in the metabolic syndrome in both developed and developing economies [9-12]. Western diet is characterized with energy

*Address correspondence to this author at the Chronobiology and Pathology, Russian,s People Friendship University, 117198, Moscow, Russia; Tel/Fax: 495787 38031958;

E-mail: Chibisov@med.rudn.ru dense, refined, ready prepared foods with a high glycemic index (e.g., refined starches; bread, biscuits, candies, cornflakes, peeza, potato chips, cola drinks and sugar) and unhealthy lipids (e.g., trans fats, saturated fat, $\omega-6$ rich oils) poor in phytochemicals and fiber. Such diets have been adopted by increased number of people and populations in the Western world and in the urban populations of middle income countries in the last few decades [1-11]. These diets are known to predispose the epidemic of NCDs. Cardiovascular disease (CVD), diabetes mellitus, obesity, cancer, autoimmune diseases, rheumatoid arthritis, asthma and depression are associated with increased production of thromboxane A2 (TXA2), leucotrienes, prostacyclin, interleukins1 and 6, tumor necrosis factor-alpha and C-reactive proteins [13-21]. Increased dietary intake of w-6 fatty acids is known to enhance all these biomarkers as well as atherogenicity of cholesterol which has adverse proinflammatry effects resulting into NCDs [14-20]. Recent studies indicate that Mediterranean diet rich in fruits, vegetables, nuts, canola oil, olive oil as well as physical activity, and meditation can decrease inflammation and may be protective against risk of CVD and all cause mortality [4, 17, 22-29]. Inflammation appears to be an important unifying hypothesis, because one 
be an important unifying hypothesis, because one recent study [21] has demonstrated that decline in inflammation can cause significant reduction in all cause mortality and cardiovascular events.

Recently, Chibisov and coworkers [7] have demonstrated the 9-year biophysical monitoring of spatial and time effects of space weather and atmospheric climatic factors on the health status of healthy subjects at latitudes. This study showed that the role of atmospheric and climatic factors in modification of dynamic regimens of human body functioning was greater in subjects living at lower latitudes. The spatial and time regularities of the effects of space and physical factors were studied which indicate

That heliomaganetic turbulence can influence cardiac function resulting in to electrocardiographic rhythm disturbances. Although, premature beats may occur due to increased release of catecholamines during magnetic turbulence, it is likely that premature beats may be a manifestation of magnetic damage to cardiomyocytes. It is also possible that magnetic turbulence can damage adipocyte, endothelial cells, mononuclear cells, smooth muscle cells and beta cells of pancreas which are very susceptible for dysfunctioning, if there is deficiency of w-3 fatty acids in the phospholipids of the cell membranes [9, 13-16]. Magnetic turbulence may also cause glycemia, release of superoxide anion, which can damage the mononuclear cells resulting into increased levels of proinflammatory cytokines. These cytokines; tumor necrosis factor (TNF)-alpha, interleukin (IL)-6,IL-18 and Creactive proteins are proinflammatory which can damage the endothelium causing endothelial dysfunction and other concerned organs of the body resulting into NCDs.

\section{BURDEN OF NONCOMMUNICALE DISEASES}

NCDs, principally CVD, cancer, chronic respiratory disease and diabetes mellitus caused 35 million deaths, which were $60 \%$ of total deaths in the year 2005. CVDs are the leading chronic diseases, with 17 million deaths. Deaths due to diabetes are usually recorded as being deaths due to heart disease, stroke and renal failure [1]. Coronary artery disease (CAD) was the cause of death, among 7.6 million and 5.7 million deaths were due to stroke. Majority of these deaths $(80 \%)$ occurred in low and middle income countries. The total world population in 2007 was 6.6 billion including 1.3 billion South East Asians, which would increase to 7.9 billion and 1.6 billion respectively by the year 2025. Adult population aged 20-79 years, in the world was 4.1 billion, including 770 million South East Asians, in the year 2007, which would increase to 5.2 billion and 1083 million respectively by the year 2025. In one recent study [8], all causes mortality were; infectious diseases $(41.1 \%, \mathrm{n}=915)$ such as tuberculosis, pneumonia, chronic obstructive pulmonary disease, diarrhea/dyssentary, hepatitis B, inflammatory brain infections as the commonest cause of deaths in the urban population of north India. The second most common causes of deaths were circulatory diseases $(29.1 \%, \mathrm{n}=646)$ including heart attacks $(10.0 \%)$,stroke $(7.8 \%)$, valvular heart disease $(7.2 \%, \mathrm{n}=160)$, sudden cardiac death and inflammatory cardiac disease, each $(2.0 \%, \mathrm{n}=44)$. Malignant neoplasm $(5.8 \%$, $\mathrm{n}=131)$, injury $(14.0 \%, \mathrm{n}=313)$ including accidents, fire and falls and poisonings, were also quite common causes of death. Miscellaneous causes of deaths were noted in $9.1 \%$, $(n=202)$ death records, including diabetes mellitus $(2.2 \%, 49)$, suicides $(1.8 \%, \mathrm{n}=41)$, congenital anomalies $(1.0, \mathrm{n}=37)$, dental caries infections $(1.9, \mathrm{n}=42)$, and burns $(1.3 \%, \mathrm{n}=33)$. Pregnancy and perinatal causes $(0.72 \%, \mathrm{n}=15)$ were not commonly recorded in this study. Circulatory diseases as the cause of mortality were significantly more common among higher social classes 1-3 than in lower social classes 4 and 5 who died more often, due to infections. Heart attacks, stroke, hypertension, diabetes and obesity were significantly more common among higher social classes 1-3 compared to class 3 and 4 but tobacco intake showed only minor differences in various classes. According to Registrar General of India, in the year 1994 to 1998 , trends indicate that there has been a significant decline of proportionate deaths from infectious diseases from $22 \%$ to $16 \%$. However, mortality from cardiovascular disease(CVD) increased from $21 \%$ to $25 \%$ which is lower than death rate of 29.1 reported by Singh et al. in 2005 [8].

CVD is also responsible for much of disability, for several decades of each patient,s life. Nearly half of the global burden of disease is caused by NCDs, which include, stroke and CAD as the leading contributor among these diseases (1, 29-30). The number of deaths by CVD appears to be similar in men and women, although the average age of onset is older in women than in men $[31,32]$. CVD deaths are spread evenly among the developed and developing world, although higher social classes in developing countries and lower social classes in developed countries have greater prevalence and risk of CVD [1, 8, 31, 32]. Of the total world's population, $80 \%$ of them live in developing countries and $80 \%$ of all CVD deaths occur in countries with a per capita income in 2001 of less than US\$90000 per year. CVD death rates in middle aged people are considerably higher in low and middle income countries, than in developed countries [33]. This situation was also present in USA and Western Europe in 1960s. The greatest differences in risk distribution of CVD are observed within low and middle income countries [1, 33]. CVD have a major and unrecognized impact on health of the working people and the economic development of the developing world $[1,33]$.

In Europe, major NCD are responsible for $85 \%$ of deaths and $70 \%$ of the disease burden. The costs for the care of consequences of NCD present an enormous burden for the economy of the country in addition to the human suffering, even in those more affluent Member States where one sees downward trends in NCD mortality (primarily CVD, cancer, chronic obstructive pulmonary disease (COPD) and diabetes). Chronic disease places an enormous health and economic burden on the population of all Member States of the WHO European Region. Multiple risk factors management is a critical area in the prevention and therapy of NCD and it has been shown to be effective in reducing mortality and disability mainly in CVD.

The development of studies and the impact of innovative medicine tools in both risk prevention and treatment of events have had a dramatic impact recently on the mentioned scenario. Unfortunately, there continue to be many barriers which prevent reaching the clinical goal both in the individual patient and in the high risk population. Although CVDs have a significant impact on national economies by disabling and killing the working-age population, the health systems of 
most European countries as well as throughout the world are not adequately structured to respond to these emerging needs. Barriers that obstruct the dissemination of information on the early diagnosis, treatment, and prevention of multiple risk factors in disease in many countries, are particularly high. Some of the barriers are linked to a lack of integrated country-specific policies. Evidence shows that the NCD (as CVD, obesity, diabetes, COPD and some tumours) burden on lives and economy can be decreased by appropriate integrated approaches to health policies applied to: individual risk reduction (aimed at high-risk individuals), population risk reduction (aimed at social determinants), rational use of health services (by empowering primary health care), and referral system support and help from non-government organizations.

\section{GOALS FOR HUMAN DEVELOPMENT IN RELA- TION TO NONCOMMUNICABLE DISEASES}

The impact of NCDs, in particular CVD was examined on 5 countries and reported that it could have a serious effect on human and national development $[1,33]$. The total number of years of productive life lost for the five countries in people aged 35 to 64 years would increase from 20.6 million in 2000 to 33.7 million in 2030. The World Health Organization estimated full-income losses due to heart disease, stroke and diabetes mellitus in 9 countries and found that these conditions were responsible for huge amounts of national income (1). CVD develop in association with economic development in the country, first increase among higher social classes, such as is in India, China, Russia. Soon after learning the method of prevention, there is a decrease in CVD risk among higher social classes, and the risk concentrates among lower social classes, as in the developed countries. There is greater susceptibility of the lower social classes, because of these risk factors are amplified by stress, higher levels of environmentally induced risk behaviours, and limited access to high quality and affordable health care and healthy diet and lifestyle.

The epidemiological evolution of CVDs among subjects of African origin living in the United States and among people living in other developing countries has many similarities [34]. In most developing populations, there are six stages of epidemiological transition, characterized by indices of acculturation, urbanization, affluence, saturated fat intake, salt intake and tobacco consumption. A sedentary lifestyle and psychological stress appear to play important role during various stages of transition. The prevalence of CVD and diabetes mellitus initially shows an increase with a rise in these factors. The emergence of chronic diseases in most developing countries, in the last few decades is an example of epidemiological transition because in 1970s, CVD and diabetes mellitus were rare in these countries [6-10]. These developing populations appear to be under transition from poverty to affluence. The World Development Report (1993), in which affluence was measured by evaluation of per capita net domestic product, growth of production and the human development index, the per capita net domestic product, which was 558 in 1961 and 737 in 1981, increased to 931 in 1991 [35]. The annual growth rate in gross domestic product, which was $3.4 \%$ in $1970-1980$, increased to $5.4 \%$ in 1980 1991 and now it is about $7.5 \%$ in 2009. This increase of $2.0 \%$ in gross domestic product and marked increase in an- nual growth rate are more than that found in many developed countries, indicating rapid socioeconomic transition in India and other developing countries like China, Russia, Thailand, Philippines, Pakistan, Bangladesh, Nepal, Sri Lanka, Brazil, Mexico, Vietnam etc. The human development index in Indians in which longevity, income and knowledge were measured, showed that life expectancy at birth has increased from 41.3 years in 1961 to 60.8 years in 1991 and 65 years in 2009. The human development index was 0.258 in 1970 , which increased to 0.309 in 1990 . These characteristics of human development were associated with marked increase in the production of tobacco, salt, sugar and dietary fat as well as an enormous increase in automobiles, causing sedentary behaviour during the last 4 decades of development in India [35]. A similar situation was observed in all other developing countries, especially in middle income countries including eastern European countries [33-45].

In most developed countries, people with NCD, particularly CVD, are protected by social security systems and reasonable health insurance, which enables them to buy necessary health care [36, 37]. In developing countries, the health insurance systems are just developing and the cost of care for CVD are borne individually hence treatment remains incomplete. The connection between lower socioeconomic status and NCDs, extends beyond prevention and includes health education and its implementation.

In Europe, Western European countries show very little further development as they are now fully developed. However, middle and eastern European countries indicate a rapid development after disintegration of USSR and formation of European Union. It is critical that European authorities promote, along with the medical community, the new total risk management strategy. Failure to replace the current treatment paradigm-based on weak and limited intervention from authorities and focused on single risk factors by the medical community - with a more comprehensive and integrated (in terms of the involved stakeholders as well) approach will result in missed opportunities to reverse the current epidemic of CVD [36-45]. After World War II, significant improvements in health developed across Europe. By the 1970s, however, while life-expectancy in the West had continued to rise, in Central and Eastern Europe and in the Former Soviet Union, life expectancy began to plateau, or more worryingly, decrease. This gap in life expectancy, still evident today, is mainly due to mortality from circulatory diseases. Available data suggest classical risk factors account for only a part of this difference between populations; it is therefore likely that other risk factors are involved. The high cardiovascular mortality in Eastern Europe has often been attributed to poor diet, but individual-level data on nutrition in the region are generally not available. In one study [45], the methods of dietary assessment and presents preliminary findings on food and nutrient intakes in large general population samples in Russia, Poland and the Czech Republic were obtained. The HAPIEE (Health, Alcohol and Psychosocial factors In Eastern Europe) study examined random samples of men and women aged 45-69 years at baseline in Novosibirsk (Russia), Krakow (Poland) and six Czech urban centres in 2002-2005. Diet was assessed using a food frequency questionnaire (at least 136 items); complete dietary information was available for 26,870 persons. Total energy intakes among men ranged between 8.7 $\mathrm{MJ}$ in the Czech sample and 11.7 $\mathrm{MJ}$ in the 
Russian sample, while among women, energy intakes ranged between 8.2 MJ in the Czech sample and 9.8 MJ in the Russian sample. A Healthy Diet Indicator (HDI), ranging from a score of 0 (lowest) to 7 (highest), was developed using the World Health Organisation's (WHO) guidelines for the prevention of chronic diseases. The mean HDI scores were low, ranging from $1.0(\mathrm{SD}=0.7)$ among the Polish subjects to 1.7 $(\mathrm{SD}=0.8)$ among the Czech females. Very few subjects met the WHO recommended intakes for complex carbohydrates, pulses or nuts; intakes of saturated fatty acids, sugar and protein were too high. Only $16 \%$ of Polish subjects met the WHO recommendation for polyunsaturated fat intake. Consumption of fruits and vegetables was lower than recommended, especially among those Russian subjects who were assessed during the low intake season. Fewer than $65 \%$ of subjects consumed adequate amounts of calcium, magnesium and potassium, when compared with the United Kingdom's Reference Nutrient Intake. This first large scale study of individual-based dietary intakes in the general population in Eastern Europe implies that intakes of saturated fat, sugar and complex carbohydrates are a cause for concern. The development of country-specific nutritional tools must be encouraged and nutritional campaigns must undergo continuing development.

There is need to adopt TT Concept approaches; which include major emphasis on control of primary risk factors; diet, sedentary behaviour, stress, tobacco and alcoholism for prevention of NCDs. This challenge of educating the people and population on health and prehabilitation, would be met with the establishment of Tsim Tsoum Institute at Krakow in Poland. There is recognition that a small number of risk factors are common to major NCDs. The simultaneous reduction of these common risk factors would reduce the major NCDs and improve public health. This concept emphasizes health promotion and disease prehabilitation through existing health care systems and the active participation both of communities and of individual. There is a need for European authorities to integrate interventions that are aimed at several risk factors within the country's healthcare system; to have a comprehensive approach that combines various implementation strategies, including policy development, capacity building, partnership and information support at all levels; to promote transversal health policies, including coordinated action by several sectors; development of designer foods and cropses, gyms and sports, banning of tobacco for human consumption, cheaper wines, more expensive other alcohol products, introduction of yoga and meditation in schools, to address major determinants of ill health that fall outside the purview of the health sector. It may be important to combine health policy and high-risk strategies which would link the preventive action of various components of the healthcare system such as health promotion, public health services, primary care, and hospital care. In a new biologic perspective, it has been described that high risk subjects may have high-risk plaque as a "disorder of homeostasis" whereby the repair or inflammatory response to lipid deposition, endothelial damage, and red blood cell leakage from the vasa vasorum is either too little or too active, or the cells become exhausted and apoptotic, releasing toxic substances [39]. Recent evidence indicates that the main therapeutic approach to prevent plaque destabilization and rupture is statin treatment [21]. Statins appear to dampen the inflammation and remove and replace lipid deposits with connective tissue, with resulting regression of the plaque. Studies have demonstrated this effect on subclinical atherosclerosis in asymptomatic individuals, as well as in patients with established, symptomatic disease [40]. There is a need to conduct similar studies using Mediterranean diet rich in w-3 fatty acids with w-6/w-3 ratio of 1:1 in the regression of atherosclerosis because mounting evidence indicate that such a diet can cause significant reduction in CVDs mortality and all cause mortality (23). International agencies like WHO, International College of Nutrition and International College of Cardiology and the BIOCOS group are planning several strategies for prevention of NCDs in the world [46-51].

\section{THE TSIM TSOUM CONCEPT}

Modern man appears to live in an environment that completely differs from that his genetic constitution was selected for. Our genes appear to be similar to the genes of our ancestors during the Paleolithic period 40,000 years ago, the time when our genetic profile was established. However, it was only during the last 100-150 years, and even more so over the past 50 years, that dietary intakes and lifestyles have changed significantly, causing increased intakes of saturated fatty acids (SFA) and linoleic acid (LA), and decreased intakes of $\omega 3$ fatty acids, from grain-fed cattle tamed at farm houses rather than meat from hunted free-roaming animals. The food and nutrient intakes among hunter-gatherers during the Paleolithic period were fruits, vegetables, seeds, whole grains, egg, fish and wild animal meet which were low in w6 and high in w-3 fatty acids along with antioxidants and vitamins. In comparison to modern diets, there is a marked reduction in consumption of $\omega 3$ fatty acids, vitamins, minerals and proteins, and a significant increase in intakes of carbohydrates (mostly refined), fats (saturated and unsaturated trans fats, linoleic acid) and salt.

The Columbus Concept of diet takes as granted that humans evolved on a diet low in saturated fats and balanced in $\omega 3$ and $\omega 6$ fatty acids $(9,14)$. Nature appears to recommend dietary balanced fatty acids ratios $(P: S=\omega 6: \omega 3=1: 1)$ as part of a global dietary lipid pattern high in monounsaturated fatty acids (P: $M: S=1: 6: 1)$. These ratios represent the overall averaged distribution of fats in a natural untamed environment (www.columbus-concept.com). Columbus foods include egg, milk, meat, oils and bread, all rich in $\omega 3$ fatty acids, similar to wild foods consumed until some 150 years ago. Blood lipid composition does reflect one's health status: (a) circulating serum lipoproteins and their ratio provide information on their atherogenicity to blood vessels and (b) circulating plasma fatty acids, such as $\omega 6 / \omega 3$ fatty acids ratio, give indication on pro-inflammatory status of blood vessels; (a) and (b) are phenotype-related and depend on genetic, environmental and developmental factors. As such, they appear as universal markers for holistic health. Blood cholesterol is central to this approach [9, 14]. Its 3Drepresentation shows how circulating lipoproteins affect blood vessels integrity upon their circulating throughout the body. Of major importance appear the essential dietary nutrients (essential amino acids, fatty acids, antioxidant vitamins and minerals) and the functional components of the regimen (diet-functional nutrients, sport, spiritualism, etc). The TsimTsoum Concept (YYTT) is an extension of the 
Columbus Concept (YYCC). While YYCC is a 1-D approach that establishes the basis for the "essential" components of the diet, YYTT is a 2-D approach that focuses on the "functional" components of the lifestyle: functional foods, positive stress, physical training, meditation. YYCC and YYTT are complimentary and do not compete against each other. Chronobiology is an important aspect of YYTT because it is based on mind-body interactions which could be modulated by dietary choices, physical \& mental activity, meditation, and the like, all leading to human development (http://www.tsimtsoum.net/introduction_07.php). The YYTT approach favors the analysis of memes-genes interactions, i.e., that of (human's influence on nature (genes), and therefore also that of the influence of nurture and environment on human health and behavior [14]). Therefore, YYTT approaches for prehabilitation of chronic diseases of affluence are similar to those of WHO and include dietary modification, moderate physical activity, meditation and yoga, cessation of tobacco and alcoholism and advise for wine to those who prefer drinking, with an aim to target genes and memes. There is a greater emphasis on genes and memes because recent evidence indicate that chronic diseases of affluence, at least in part are diseases of the brain.

\section{MECHANISMS AND INTERACTIONS OF RISK FACTORS}

We understand that chronic diseases of affluence; CVD, diabetes mellitus, obesity, cancer, autoimmune diseases, rheumatoid arthritis, asthma and depression are associated with increased production of proinflammatory biomarkers; thromboxane A2(TXA2), leucotrienes, prostacyclin, interleukins- 1 and 6, tumor necrosis factor-alpha and C-reactive proteins [13-21] Increased dietary intake of w-6 fatty acids especially in conjunction with deficiency of antioxidants and vitamins, is known to enhance all these biomarkers as well as atherogenicity of cholesterol which have adverse proinflammatry effects resulting into CVDs and other NCDs (1420) We know that NCDs occur due to interaction of environmental factors and genetic susceptibility $[9,14]$. However, genetic do not mean nonnutritional or that genetic predisposition can not be modulated. There is consistent evidence that dietary factors and physical activity, mental stress and environmental toxicants influence gene expression and have shaped the genome over several million years of human evolution. There is opportunity for health, as well as susceptibility to diseases, through genes, while environmental factors determine which susceptible individuals will develop metabolic syndrome. Rapid changes in diet and lifestyle due to socioeconomic changes provide added stress causing exposure of underlying genetic predisposition to chronic diseases such as type 2 diabetes, obesity, hypertension, CAD and atherosclerosis. Several studies are continuing on the role of nutrients in gene expression [13-16]. It is not clear how n-3 fatty acids suppress or decrease the mRNA of interleukin, which is elevated in atherosclerosis, arthritis and other autoimmune diseases, whereas n-6 fatty acids have no such effects.

Chronobiology is the only science, which establishes a clear relation between brain and body functions [46-51]. Environmental factors causing damage during fetal life may have lifetime consequences, which may be described as pro- gramming or adaptations or microcompititions. A recent study by Chibisov et al. [51] showed that heliomagnetic fluctuations can cause cardiac dysfunctions. The damage to the neural and psychiatric mechanisms may continue from antenatal period, during infancy, childhood and in the later years of life [9]. The hormonal signals, nutritional factors and environmental toxicants may serve as signals for programming or adaptations. It is possible that these protective mechanisms developed during scarcity, serve to program the development of insulin resistance, central obesity, hypertension, type 2 diabetes, and CAD in later life, and also possibly cancer, and other NCDs, due to dysfunction of the brain. The human brain is quite rich in long chain polyunsaturated fatty acids (PUFA) such as arachidonic acid, eicosapentaenoic acid(EPA) and docosahexaenoic acid(DHA) [23-25]. These fatty acids are neuroprotective and constitute $30 \%$ to $50 \%$ of the total fatty acids in the brain, where they are predominantly associated with membrane phospholipids [25]. Therefore, if there is a deficiency of long chain PUFA, especially during the critical period of brain growth, from the third trimester to infant age( 2 years), it may cause increased levels of TNF-alpha which is known to damage the neurons [2125]. TNF-alpha may also damage suprachiasmatic nucleus, pineal and pituitary glands, olfactory bulb and the hypothalamus, the last three are rich in insulin receptors which are important in the pathogenesis of NCDs. However, TNFalpha could be decreased by long-chain PUFA, especially, n3 fatty acids and may be enhanced due to their deficiency and due to excess of $\mathrm{w}-6$ fatty acids [21, 22]. It seems that TNF-alpha may participate in the pathogenesis of NCDs by two mechanisms; primarily by inducing insulin resistance and secondarily by interfering with functions of ventromedial hypothalamus.

\section{PREVENTION OF NONCOMMUNICALE DISEASES}

In September 2000, United Nations made Millennium declaration and set 8 Millennium development goals to focus international development efforts on decreasing global poverty by 2015 . Of the 8 Millennium Development Goals, 3 goals directly address health of the people and populations, without mention of CVDs or other chronic diseases but for human development $[37,38]$. According to WHO, we know what works, we know what it costs and we know that all countries are at risk. We have an Action Plan to avert millions of premature deaths and help promote a better quality of life for millions more [36]. The 2008-2013 Action Plan for the Global Strategy for the Prevention and Control of NCDs was developed by WHO with Member States and is based on an overall strategy for the prevention and control of NCD or chronic diseases defined in March 2000 and defines the objectives for the period 2008-2013 and the actions to be implemented [36]. The Action Plan was endorsed at the Sixty-first World Health Assembly in May 2008 by delegates from 193 Member States. The document: explains the reasons for urgent action for the period 2008-2013 aimed at the growing burden of chronic diseases on public health; provides the political framework of Action Plan, including the requirement to report global progress in 2010 and 2012; presents the main global strategy for prevention and control of NCDs, which urges Member States to develop frameworks for national policy, to establish programs, and to share their experiences. 
The WHO global goal is to reduce chronic disease death rates by $2 \%$ per year over current trends [41] which is based on CAD trends in developed countries over the past 40 years and recent changes in middle- income countries in the eastern Europe. It is possible that the WHO goal, if successful, can avert 36 million chronic disease deaths by 2015, of which half would be due to CVDs (41). Approximately one half of these deaths would be in subjects below 70 years, and $3 / 4$ th of the averted deaths would be in low and middle income countries. These benefits are likely to be translated in to better quality of human development and decreased mortality in these countries [42-46]. The WHO Action Plan includes 6 specific objectives: to raise the priority given to chronic diseases in national and global development plans and strategies for integrating strategies of prevention and control into policies across all government departments to establish and to improve national policies and plans for the prevention and control of NCDs: to promote measures to reduce the major modifiable risk factors for chronic diseases: tobacco use, unhealthy diet, lack of exercise and abuse of alcohol to promote research for prevention and control of chronic diseases to promote partnerships for the prevention and control of chronic diseases : to monitor chronic diseases and their determinants and evaluate progress at the national, regional and global level [1-5]. These efforts are definitely commendable but have some limitations because clear definition of healthy diet as well as strain and depression as a risk factor of chronic diseases using chronobiological approach have not been addressed [9, 46-57]. International College of Nutrition and International College of Cardiology in their new guidelines [23] emphasize that eating 400g/day of fruits, vegetables and nuts and another $400 \mathrm{~g} / \mathrm{day}$ of whole grains inconjunction with canola oil or blended oil containing olive oil+ $w-3$ rich oil (flexed seed oil) may be protective against CVDs, also possibly NCDs. Recently Tsim Tsoum Institute has been established at Krakow in Poland to use mind-body approaches along with primary risk factors for prevention of NCDs in the world, particularly in the Eastern Europe.

\section{ACKNOWLEDGEMENTS}

Acknowledgements are due to Tsim Tsoum Institute for their support for preparing this article.

\section{REFERENCES}

[1] World Health Organization. Preventing Chronic Disease: A Vital Investment World Heath Organization, Geneva, 2005.

[2] Joint WHO/FAO Expert Consultation. Diet, Nutrition and the Prevention of Chronic Diseases, WHO, Geneva, WHO Technical Report Series, 916, 2003.

[3] WHO Study Group. Diet, Nutrition and Prevention of Chronic Diseases, WHO, Geneva, 1990.

[4] World Health Organization. Diet and Physical Activity: a public Health Priority. World Health Organization, http:/www.who. int/diet physical activity/en/ [accessed 2009].

[5] World Health Organization. WHO framework convention on tobacco control. Available at: http:/www.whoint/tobacco/framework/ en/ [Accessed 2009].

[6] Singh RB, Pella D, Mechirova V, et al. Prevalence of obesity, physical inactivity and undernutrition, a triple burden of diseases during transition in a developing economy. The Five City Study Group. Acta Cardiol 2007; 62: 119-27.

[7] Chibisov SM, Vishnevsky VV, Ragulskaya MV. Telecommunication monitoring is a method for studies of the effect of heliomag- netic fluctuations on cardiac function. Bull Exp Biol Med 2008; 143: 765-8.

[8] Singh RB, Singh V, Kulshrestha SK, et al. Social class and all cause mortality in the urban population of north India. Acta Cardiol 2005; 60: 611-7.

[9] Singh RB, DeMeester F, Mechirova V, Pella D, Otsuka K. Fatty acids in the causation and therapy of metabolic syndrome. In Wild Type Foods in Health Promotion and Disease Prevention, editors Fabien De Meester and RR Watson, Humana Press, NJ 2008, pp. 263-284.

[10] Singh RB, IL Suh, VP Singh, S Chaithiraphan, P Laothavorn, RG Sy, NA Babilonia, ARA Rahman, S Sheikh, B Tomlinsin and N Sarraf-Zadigan. Hypertension and stroke in Asia: prevelance, control and strategies in developing countries for prevention. J Human Hyper 2000; 14: 749-63.

[11] American Heart Association Heart and Stroke Statistical Update, 2008. http://www.americanheart.org/downloadable/heart/ 1200078608862HS Stats\%202008.final.pdf

[12] Singh RB, Beegom R, Mehta AS, et al., Social class and coronary risk factors and undernutrition: a double burden of diseases among women in five Indian cities. Int J Cardiol 1999; 353: 154-65.

[13] Simopoulos AP. Importance of the ratio of omega-6/omega-3 essential fatty acids: evolutionary aspects. World Rev Nutr Diet 2003; 92: 1-22.

[14] De Meester F, Wild-type land based foods in health promotion and disease prevention: the LDL-CC:HDL-CC model. In Wild Type Foods in Health Promotion and Disease Prevention, editors Fabien DeMeester and RR Watson, Humana Press, NJ 2008, pp. 3-20.

[15] Vogel RA. 21. Eating vascular biology and atherosclerosis: a lot to chew on. Eur Heart J 2006; 27: 13-4.

[16] Esposito K, Giugiliano D. Diet and inflammation: a link to metabolic and cardiovascular diseases. Eur Heart J 2006; 27: 15-20.

[17] Kelishadi R, Mirghaffari N, Poursafa, P Gidding SS. Lifestyle and environmental factors associated with inflammation, oxidative stress and insulin resistance in children. Atherosclerosis 2009; 203: $311-9$

[18] Simopoulos AP..Is Insulin Resistance Influenced by Dietary Linoleic Acid and Trans Fatty Acids? Free Radic Biol Med 1994; $17 ; 367-72$.

[19] Simopolous AP,Genetic variation and dietary response: nutrigenetics/nutrigenomics. Asia Pac J Clin Nutr 2002; 11: S11728.

[20] Das UN. Obesity, metabolic syndrome X, and inflammation. Nutrition 2002; 18: 430-8

[21] Ridker PM, Danieison E, Fonseka FAH, et al. Reduction in Creactive protein and LDL cholesterol and cardiovascular event rates after initiation of rosuvastatin: a prospective study of the JUPITER trial. Lancet 2009; 373: 1175-82.

[22] Trichopolou A, Bamia C, Trichopolou D. Anatomy of health effects of Mediterranean diet. Greek EPIC prospective cohort study. BMJ 2009; 338: b2337.

[23] Singh RB, De Meester F, Pella D, Basu TK, Watson R. Globalization of dietary wild foods protect against cardiovascular disease and all cause mortalities? A Scientific statement from the International College of Cardiology, Columbus Paradigm Institute and the International College of Nutrition. Open Nutra J 2009; 2: 42-5.

[24] Eaton SB, Eaton SB III, Sinclair AJ, Cordain I, Mann NJ. Dietary intake of long chain polyunsaturated fatty acids during the Paleilithic period. In Simopoulos AP edition. The return of w-3 fatty acids in the food supply. Land based Animal Food Products and their Health Effects. World Rev Nutr Dietetics 1998; 83: 12-23.

[25] de Lorgeril M, Renaud S, Mamelle N, et al. Mediterranean alpha-linolenic acid-rich diet in secondary prevention of coronary heart disease. Lancet 1994; 343: 1454-9. Erratum in: Lancet 1995, 345:738.

[26] Renaud S, de Lorgeril M, Delaye J, et al. Cretan Mediterranean diet for prevention of coronary heart disease. Am J Clin Nutr 1995; 61(6 Suppl): 1360S-7S.

[27] Singh RB, Gupta A, Pella D, Kumar A. Circadian Cardiology. World Heart J 2008; 1: 101-26.

[28] Dubnov Gal, Pella D, Singh RB. The effect of an alpha-linolenic acid rich diet on the circadian rhythm of cardiac events. World Heart J 2008; 1: 49-56.

[29] Labrador MP, Polk D, Dwyer JH, et al. Effects of randomized, controlled trial of Transcendental meditation on components of 
metabolic syndrome in subjects with coronary heart disease. Arch Intern Med 2006; 166: 1218-24.

[30] Levi F, Lucchini F, Negri E, La Vecchia C. Trends in mortality from cardiovascular and cerebrovascular diseases in Europe and other areas of the world. Heart 2002; 88: 119-24.

[31] Rodriguez T, Malvezzi M, Chatenoud L, et al. Trends in mortality from coronary heart and cerebrovascular diseases in Americas: 1970-2000. Heart 2006; 92: 453-60.

[32] Raymond SU, Greenberg HM, Leeder SR. Beyond reproduction: women,s health in todays developing world. Int J Epidemiol 2005; 34: $1144-8$.

[33] Leader SR, Raymond SU, Greenberg HM, Hui L, Esson KA Race Against Time: The Challenge of Cardiovascular Disease in Developing Economies. New York, NY: Columbia University; 2004.

[34] Gillum RF. The epidemiological evolution in pattern of cardiovascular diseases in blacks. N Engl J Med 1996; 335: 1597-9.

[35] World Bank. Invest in Health. World Development Report 1993, Oxford, Oxford University Press, 1993; 195-324.

[36] World Health Organization. The 2008-2013 Action Plan for the Global Strategy for the Prevention and Control of Noncommunicable Diseases (Action Plan http://www.who.int/nmh/Actionplan-PCNCD-2008.pdf

[37] Beaglehole R, Reddy S, Leeder SR. Poverty and human development. The global implications of cardiovascular disease (Editorial). Circulation 2007; 116: 1871-3.

[38] Fuster V, Voute J, MDGs: Chronic diseases are not on the agenda. Lancet 2005; 366: 1512-4.

[39] Moreno P, Sanz J, Fuster V. Promoting mechanisms of vascular health. J Am Coll Cardiol 2009; 53: 2315-23.

[40] Razzouk L, Farkouh ME. Imaging outcomes in cardiovascular clinical trials. Nat Rev Cardiol 2009; 6: 524-31.

[41] Strong K, Mathers C, Leeder S, Beaglehole R. Preventing chronic diseases: how many lives we can save? Lancet 2005; 366: 1578-82.

[42] Wang L, Kong L, Wu F, Bai Y, Burton R. Preventing chronic diseases in China. Lancet 2005; 366: 1821-4.

[43] Jamison DT, Breman JG, Measham AR, et al., eds. Disease control priorities in developing countries. $2^{\text {nd }}$ edition, New York, Oxford University Press/World University Press/World Bank; 2006.

[44] Mesle F. Mortality in Central and Eastern Europe: long-term trends and recent upturns. Demogr Res 2004; 2: 45-70.
[45] Boylan S, Welch A, Pikhart H, et al. Dietary habits in three Central and Eastern European countries: the HAPIEE study. BMC Pub Health 2009; 9: 439-45.

[46] Singh RB, Cornelissen G, Weydahl A et al. Circadian heart rate and blood pressure variability considered for research and patient care. Int J Cardiol 2003; 87: 9-28.

[47] Sundaram B, Holley DC, Cornelissen G, et al. Circadian and circaseptan ( about weekly) aspects of immigrant Indians blood pressures and heart rate in California, USA. Biomed Pharmacol 2005; 59: S76-85.

[48] Cornélissen, G, Halberg F, Otsuka K, Singh RB, Chen CH. Chronobiology predicts Actual and proxy outcomes when dipping fails. Hypertension 2007; 49: 237-9.

[49] Halberg F, Cornélissen G, Ulmer W, et al. Chronomics for cancer, aging, melatonin and experimental therapeutics researchers. J Exp Ther Oncol 2006; 6: 73-84.

[50] Halberg F, Cornélissen G, Otsuka K, et al. Extended consensus on need and means to detect vascular variability disorders (vvds) and vascular variability syndromes (vvss). Int J Gerontol Chronome Geriatr 2008; 11: 119-46.

[51] Ragulskaya MV, Pipin VV, Chibisov SM. The dynamical properties of the human EGC in the light of tele-communicational heliomedical monitoring("Heliomed") People,s Friendship University Chronobiology Chronomedicine Symposium, Moscow, Feb 7, 2010.

[52] Pednekar MS, Gupta R, Gupta PC. Association of blood pressure and cardiovascular mortality in India: Mumbai Cohort Study. Am J Hypertens 2009; 22(10): 1076-84.

[53] Paoletti R. Nutrition and noncommunicale diseases. www. healtheurope.org [Accessed December 17, 2009].

[54] Nanda S, Mishra S, Varshney VP, Singh RB. A Biotechnological Approach to Apoptosis of Somatic and Germ Cells in Living Organisms. Open Nutra J 2010; 3: 81-93.

[55] Mudgal V, Madaan N, Mudgal A, Singh RB, Mishra S. Effect of Toxic Metals on Human Health. Open Nutra J 2010; 3: 94-9.

[56] Nanda S, Mishra S, Varshney VP, Tyagi A, Singh RB. Cytotoxic Effect of Syzgium aromaticum Extract and Gemcitabine on $\mathrm{Hu}$ man Cervical Cancer Cell Line. Open Nutra J 2010; 3: 69-75.

[57] Sharma V, Kalim S, Srivastava MK, Nanda S, Mishra S. Oxidative stress and coxsackievirus infections as mediators of beta cell damage: A review. Sci Res Essays 2009; 4(2): 42-58.

This is an open access article licensed under the terms of the Creative Commons Attribution Non-Commercial License (http://creativecommons. org/licenses/ by-nc/3. 0/) which permits unrestricted, non-commercial use, distribution and reproduction in any medium, provided the work is properly cited. 